\title{
DISCURSO E TRADUÇÃO EM ANTOLOGIAS BILÍNGUES
} (Poesia Argentina em Espanhol, Português e Francês)

\author{
Silvana Serrani \\ UNICAMP - IEL \\ silvana.serrani@gmail.com
}

\section{Introdução}

As antologias têm tido papel relevante nas práticas letradas de gerações de leitores, na representação de literaturas nacionais, na confirmação ou transformação de cânones, na educação, no desenvolvimento da crítica, no aprofundamento de concepções de cultura etc. Isso fez com que em muitas sociedades, ao longo da história, o gênero tenha recebido especial consideração, materializada em projetos editoriais, educacionais, de tradução ou de pesquisa sistemática ${ }^{1}$. A participação das antologias nas consolidações nacionais do passado não deixa de existir hoje na conjuntura de construção de blocos geopolítico-culturais. Por exemplo, no caso da União Europeia, estudos recentes mostram a produção de antologias literárias vinculada a diferentes concepções da construção da chamada "identidade cultural europeia"2. Na Ibero-América, apesar da relevância do gênero, a antologia, em sua especificidade, ainda não tem recebido suficiente atenção analítica. Assim, este trabalho procura contribuir para essa indagação. Ele é resultado de uma pesquisa mais ampla sobre compilações de múltiplos autores de poesia latino-americana. O projeto aborda a antologia 
enquanto gênero discursivo e lugar de memória (Bakhtin, 1984; Foucault, 1985; Pêcheux, 1990; Nora, 1996) ${ }^{3}$. No caso específico das edições bilíngues, o enfoque está norteado pelos estudos sobre produção e disputa de capitais simbólicos, a partir do pensamento de Bourdieu. Como diz sua discípula Pascale Casanova (2002: 55), "as literaturas não são a emanação de uma identidade nacional, elas são construídas na rivalidade (sempre negada) e na luta literária, sempre internacionais". Nas antologias bilíngues, a tradução é, obviamente, condição de existência e, em relação a outras situações de literatura traduzida, a singularidade de mostrar pontualmente as versões justapostas em línguas diferentes permite levantar questões específicas sobre materialidade discursiva, que remetem simultaneamente à instância da letra e à chamada tradução cultural, como procuro mostrar a seguir.

Neste texto abordo a tradução em antologias bilíngues sob três ângulos: a representação do projeto tradutório no discurso das antologias; a comparação de traduções efetivas de um mesmo poema em mais de uma antologia e a relação entre crítica e estrutura composicional nas antologias. Estarão em foco as compilações pioneiras de poesia argentina em espanhol e português: Poesia Argentina 1940-1960, de Bella Jozef (doravante: Poesia 40/60) ${ }^{4}$, e a antologia bilíngue Puentes/Pontes - Poesia Argentina e Brasileira Contemporânea, de Jorge Monteleone e Heloísa Buarque de Hollanda (doravante: Puentes/Pontes) ${ }^{5,6}$. Em um momento da análise, farei referência também à antologia em espanhol/francês Poésie argentine du XXe siècle (doravante: Poésie), organizada por Horacio Salas, com tradução de Nicole Priollaud ${ }^{7}$.

Na primeira parte do trabalho, discuto a representação da tradução nos prefácios ou ensaios preliminares, ou seja, no que Genette (2002: 10-11) chama de paratexto e que nos estudos do discurso, em investigações transdisciplinares com o campo da História, tem sido abordado também enquanto fontes secundárias para a análise de práticas verbais e expressivas ${ }^{8}$. Na segunda parte, abordo a materialidade poético-discursiva, mediante a discussão de opções tra- 
dutórias de um mesmo poema em mais de uma antologia. Os exemplos serão "O expulso", de Juan Gelman, nas antologias Puentes/ Pontes e Poésie e os dois poemas que constam em ambas as antologias em espanhol/português citadas: "Olga Orozco", da autora homônima, e "Infância", de Alejandra Pizarnik. Na terceira parte, observo a relação entre as cartografias dos estudos preliminares e as apresentações efetivas dos poemas nessas antologias. Comento adicionalmente o caso da antologia monolíngue de Perednik (1992), caracterizada pela consonância direta entre o mapeamento crítico do estudo preliminar e a estrutura composicional da antologia.

\section{O Discurso sobre a Tradução}

Para representar a tradução, em Poesia 40/60 predominam ressonâncias discursivas ${ }^{9}$ sobre: a tradução poética em geral; os critérios de tradução adotados nessa antologia e a relação entre as línguas envolvidas, como mostram os exemplos abaixo.

Quanto à tradução poética, há ressonâncias discursivas sobre sua concepção inventiva: "Toda tradução é uma invenção que pretende chegar a um poema - no caso - análogo ao original." (Jozef, 1990: 13).

Em relação aos critérios de tradução na antologia, ressoam sentidos sobre literalidade:

Nossa intenção foi fazer, sempre que possível, uma tradução literal e fiel, aproximando-nos do original, sem traí-lo, mas, muitas vezes, expressando o mesmo sob forma diferente. Evitamos suprimir ou acrescentar, nem sempre mantendo o compromisso da rima e do metro ${ }^{10}$. (Jozef, 1990: 13 e 14).

A respeito das línguas espanhola e portuguesa, as ressonâncias discursivas são sobre paradoxos de sua proximidade: 
Os laços de parentesco entre o espanhol e o português (cuja facilidade às vezes aparente é frequentemente um complicador, como todo parentesco) não afastam o problema semântico e fonético, das diferenças sintáticas, a pluralidade de sentido de cada palavra e a frequência do emprego de cada palavra em cada língua. (Jozef, 1990:14)

Em Puentes/Pontes, ainda que seja frequente em antologias (e em outros gêneros) a tão comentada "invisibilidade" da tradução, em se tratando de uma antologia bilíngue, não deixa de chamar a atenção a escassez de ressonâncias discursivas sobre a questão. Mas isso não significa que o projeto tenha descuidado a tradução. No caso da poesia argentina, ela foi realizada pelos reconhecidos tradutores Josely Vianna Baptista, Renato Rezende e Sérgio Alcides $^{11}$. Somente não foram traduzidos por eles os poemas "Brote de nieve", de Arturo Carrera, "El pájaro se desampara...", de Juan Gelman, e "En el final era el verbo", de Olga Orozco, que constam na antologia com traduções de Haroldo de Campos.

A tradução cultural é o tópico que ressoa no estudo preliminar dedicado à poesia brasileira nessa mesma antologia. Diz Buarque de Hollanda (2003: 279): "um projeto como este traz, de imediato, a questão da tradução cultural lato sensu que me parece ser hoje um dos grandes desafios sociais que temos pela frente". A seguir, há também ressonâncias discursivas, sobre a "traduzibilidade" maior ou menor da poesia selecionada:

(...) obedecendo à orientação do projeto de apresentar um panorama da produção poética brasileira através de vinte poetas, nascidos entre os anos 1920 e 1950, procurei compor um conjunto heterogêneo (...) de poetas mais 'universais' $e$ poetas mais 'contextuais', ou seja, aqueles que respondem mais diretamente a momentos ou conjunturas políticas e sociais locais e específicas e, portanto, relativamente menos 'traduzíveis' para outros contextos culturais. (H. Buarque de Hollanda, Puentes/Pontes: 2003: 279.) 
A questão da tradução cultural não deixa de estar presente no paratexto da parte dedicada à poesia argentina, por exemplo, em notas da tradução de poemas específicos. No caso dos poemas "Argentino Até a Morte", de César Fernández Moreno, e "Criollo do Universo", de Francisco Madariaga, os tradutores - Sérgio Alcides e Renato Rezende, respectivamente - optam por não traduzir o termo criollo, dada a diferença de sentido para crioulo em português brasileiro. Em notas, são incluídas observações léxico-culturais sobre o fato de "criollos" ser o nome dos descendentes de espanhóis nascidos nas antigas colônias da Espanha na América (cf. Puentes/ Pontes, 2003: 113 e 190).

Além do apontado, não se observam outras ressonâncias discursivas sobre a tradução no paratexto dessas antologias. A seguir, discuto aspectos da materialidade discursiva em traduções efetivas de poemas nessas compilações.

\section{Traduções Comparadas e Discurso}

Discurso, como sintetizou recentemente Eagleton (2007:2), significa "abordar a linguagem em toda sua densidade material" Nessa perspectiva, a forma linguística não é mera "contenedora" de sentidos, mas materialmente constitutiva deles. A referência ao formalismo russo feita pelo autor não é apenas relevante para melhor compreender essa corrente analítica, mas também é esclarecedora sobre o enfoque material da linguagem em geral. De fato, nas décadas iniciais do século XX, os formalistas insistiram em ver a poesia como expressão verbal autoconsciente. "Para esses audaciosos críticos de vanguarda, diz Eagleton, (...) os poemas não eram compostos de imagens, ideias, símbolos, forças sociais ou intenções do poeta, mas de palavras" (op. cit.: 48).

Nos Estudos do Discurso - baseados, entre outros, em Foucault (1985, 1987) e Pêcheux $(1988,1990 a, 1990 b)$-, a palavra não é entendida como mera referidora de significados de um mundo 
dado, mas - dito simplificada e resumidamente - como produtora de efeitos de sentido entre interlocutores reais ou representados em gêneros discursivos contextualizados, que acontecem em redes significantes de repetibilidade e contradição de instituições sociais ${ }^{13}$. Especificamente sobre a relação entre gêneros cotidiano e poético, parece-me oportuno acompanhar um extrato que fiz de afirmações recentes de Eagleton:

O tom em que eu lhe digo 'Bom dia', seja gelado ou afável, pode fazer uma grande diferença em seu significado. (...). Tom, cadência, timbre, ritmo, altura, etc. podem contribuir a constituir o sentido do que digo na vida cotidiana, assim como também na poesia. (...). Mas a poesia põe à mostra o que é verdadeiro de qualquer forma sobre nossa linguagem e que geralmente passa despercebido. (...). É o tipo de escrita que (...) nos dificulta que ponhamos as palavras de lado para atingir os significados. (...) [Ela] torna claro que o significado é o resultado de um jogo complexo de significantes. E ao fazê-lo, nos permite experimentar o próprio caminho de nossa experiência. (Eagleton, 2007: 67-68.)

Assim, em consonância com esse enfoque da materialidade verbal, discuto, a seguir, traduções para o português dos mencionados poemas de Gelman, Orozco e Pizarnik, nessas antologias.

$\mathrm{Na}$ tradução dos cinco primeiros versos de "el expulsado", de Gelman, em Puentes/Pontes, o critério de literalidade parece prevalecer, inclusive, em relação à manutenção de elementos de rima entre os versos dois e seis. Ela poderia ter sido mantida em portugués, se a tradução não incluísse o pronome "me", mas a tradução prioriza o número de sílabas: 


\begin{tabular}{|c|c|}
\hline "el expulsado", Juan Gelman ${ }^{14}$ & $\begin{array}{l}\text { "O expulso", Juan Gelman } \\
\text { Tradução: Sérgio Alcides }\end{array}$ \\
\hline $\begin{array}{l}1 \text { me echaron de palacio / } \\
2 \text { no me importó / } \\
3 \text { me desterraron de mi tierra / } \\
4 \text { caminé por la tierra / } \\
5 \text { me deportaron de mi lengua / } \\
6 \text { ella me acompañó / }\end{array}$ & $\begin{array}{l}1 \text { me mandaram embora do palácio / } \\
2 \text { não me importei / } \\
3 \text { me desterraram da minha terra / } \\
4 \text { caminhei pela terra / } \\
5 \text { me deportaram da minha língua / } \\
6 \text { ela me acompanhou / }\end{array}$ \\
\hline
\end{tabular}

(Puentes/Pontes, 2003:126)

O pronome "me" é, justamente, pivô do que procuro salientar. O verso sete "me apartaste de vos" está inserido em uma sequência: "me echaron de palacio", "me desterraron de mi tierra", "me deportaron de mi lengua" e "me abrasan llamas vivas". Como se vê, a materialidade verbal está marcada pelo início desse pronome, que reforça o sentido do enunciador afetado pelas ações verbais de mandar embora, desterrar etc. A terceira pessoa do plural é a ressonância discursiva do recurso generalizador de agente indeterminado ${ }^{15}$. Também, nesse mesmo verso sete, acontece a mudança crucial da passagem do agente coletivo indeterminado à esfera pessoal, íntima, constituindo o que se pode chamar de um clímax do poema. Mas na tradução de me apartaste de vos por "você se separou de mim", o foco deixa de estar no eu e passa para a ação da segunda pessoa (você):

\begin{tabular}{|l|l|}
\hline (...) & $(\ldots)$ \\
7 me apartaste de vos / y & 7 você se separou de mim / e \\
8 se me apagan los huesos / & 8 meus ossos se desvanecem / \\
9 me abrasan llamas vivas / & 9 chamas vivas me abrasam / \\
10 estoy expulsado de mi / & 10 de mim mesmo fui expulso / \\
\hline
\end{tabular}

(Puentes/Pontes, 2003: 126.)

Poder-se-ia argumentar que o sistema da língua portuguesa não permite essa recorrência de construções ${ }^{16}$. Mas, por exemplo, a tra- 
dução possível por: me afastaste de $t i^{17}$ contemplaria isso, mesmo que na variedade sociolinguística do leitor o uso da segunda pessoa pronominal com tu não fosse usual em sua linguagem cotidiana.

$\mathrm{Na}$ tradução dos versos iniciais desse mesmo poema na antologia em espanhol/francês Poésie argentine $d u X X e$. siècle, o sentido de indeterminação da terceira pessoa do plural em espanhol é expresso em francês com a construção "on-verbe": "on me chassa"; "on m'exila"; "on me déporta". Justamente a partir do sétimo verso, a tradução em francês, com estruturas de voz ativa ou passiva, mantêm o foco no eu-enunciador (afetado pelas ações de apartar/ séparer e abrasar/brûler):

\begin{tabular}{|l|l|}
\hline$(\ldots)$ & $(\ldots)$ \\
$7 \quad$ me apartaste de vos / y & 7 tu m'as séparé de toi/ et \\
8 se me apagan los huesos / & 8 j'ai les os rompus / \\
9 me abrasan llamas vivas / & 9 je suis brûlé vif/ \\
10 estoy expulsado de mi / & 10 je suis expulsé de moi/ \\
\hline
\end{tabular}

(Poésie, 1996: 276-277.)

No final do poema, em "estoy expulsado de mí", ressoa um discurso descritivo, mantido na versão em francês: "je suis expulsé de moi”. Mas, na materialidade do passado na tradução para o português, "de mim mesmo fui expulso", parecem ressoar sentidos de discurso narrativo.

Passemos agora à tradução do poema de Orozco. Na tradução de Sérgio Alcides de "Olga Orozco", em Puentes/Pontes, é mantido o sentido de instrumentalidade da construção do original: "en las manos con que otras las tatuaron" (verso seis). Na tradução em Poesia 40/60, o foco, que no original parece concentrado no eu, parece ter um sentido ampliado pela tradução por "nas mãos de outros que as tatuaram" (com construção de determinante e relativa): 


\begin{tabular}{|c|c|c|}
\hline $\begin{array}{l}\text { Olga Orozco (frag- } \\
\text { mento) }\end{array}$ & $\begin{array}{l}\text { Olga Orozco (frag- } \\
\text { mento) }\end{array}$ & $\begin{array}{l}\text { Olga Orozco (frag- } \\
\text { mento) }\end{array}$ \\
\hline $\begin{array}{l}\text { De Olga Orozco } \\
\text { Puentes/Pontes: } 207\end{array}$ & $\begin{array}{l}\text { Tradução: Sérgio Al- } \\
\text { cides Puentes/Pon- } \\
\text { tes: } 207 \text {. } \\
(\ldots)\end{array}$ & $\begin{array}{l}\text { Tradução de Bella } \\
\text { Jozef } \\
\text { Poesia 40/60: } 97 . \\
(\ldots)\end{array}$ \\
\hline $\begin{array}{l}07 \text { Mi historia está en } \\
\text { mis Imanos y en las } \\
\text { manos con Ique }\end{array}$ & $\begin{array}{l}07 \text { Minha história } \\
\text { está em [minhas } \\
\text { mãos e nas mãos } \\
\text { lcom que }\end{array}$ & $\begin{array}{l}07 \text { Minha história } \\
\text { está em minhas mãos } \\
\text { e nas mãos [de }\end{array}$ \\
\hline 08 otros las tatuaron. & $\begin{array}{l}08 \text { outros as tatua- } \\
\text { ram. }\end{array}$ & $\begin{array}{l}08 \text { outros que as ta- } \\
\text { tuaram. }\end{array}$ \\
\hline $\begin{array}{l}09 \text { De mi estadía que- } \\
\text { dan llas magias y los } \\
\text { ritos, }\end{array}$ & $\begin{array}{l}09 \mathrm{Da} \text { minha estadia } \\
\text { [restam as magias e } \\
\text { os ritos, }\end{array}$ & $\begin{array}{l}09 \text { De minha estada } \\
\text { ficam [as magias e os } \\
\text { ritos, }\end{array}$ \\
\hline $\begin{array}{l}10 \text { unas fechas gasta- } \\
\text { das por el soplo de un } \\
\text { [despiadado amor, } \\
\text { (...) }\end{array}$ & $\begin{array}{l}10 \text { certas datas gas- } \\
\text { tas pelo sopro de um } \\
\text { amor [impiedoso, } \\
(\ldots)\end{array}$ & $\begin{array}{l}10 \text { algumas datas gas- } \\
\text { tas pelo sopro de um } \\
\text { amor [desapiedado, } \\
(\ldots)\end{array}$ \\
\hline
\end{tabular}

Em relação ao léxico, chama a atenção a tradução de "despiadado" do verso oito por "desapiedado", de uso bem menos frequente que o adjetivo "impiedoso", na tradução de Puentes/Pontes. Na opção de traduzir "quedan" por "ficam", Jozef parece reforçar o sentido (não substrativo) da presença (de magias e ritos). No espanhol existe o verbo "restar" (da tradução de Alcides em Puentes/ Pontes), mas não foi escolhido por Orozco no original.

A seguir, as questões salientadas na tradução de "Infância", de Pizarnik, pretendem ilustrar a reflexão sobre escolha lexical em relação a sonoridades fonêmicas e a memórias discursivas. Por exemplo, a opção pela palavra "relva" na tradução de Alcides em Puentes/Pontes se afina com a materialidade vocálica do original "yerba" e a escolha pelo nome "Alice" parece levar mais em consideração (do que a manutenção de "Alicia") as ressonâncias discursivas do título em português da obra aludida de Carroll. 


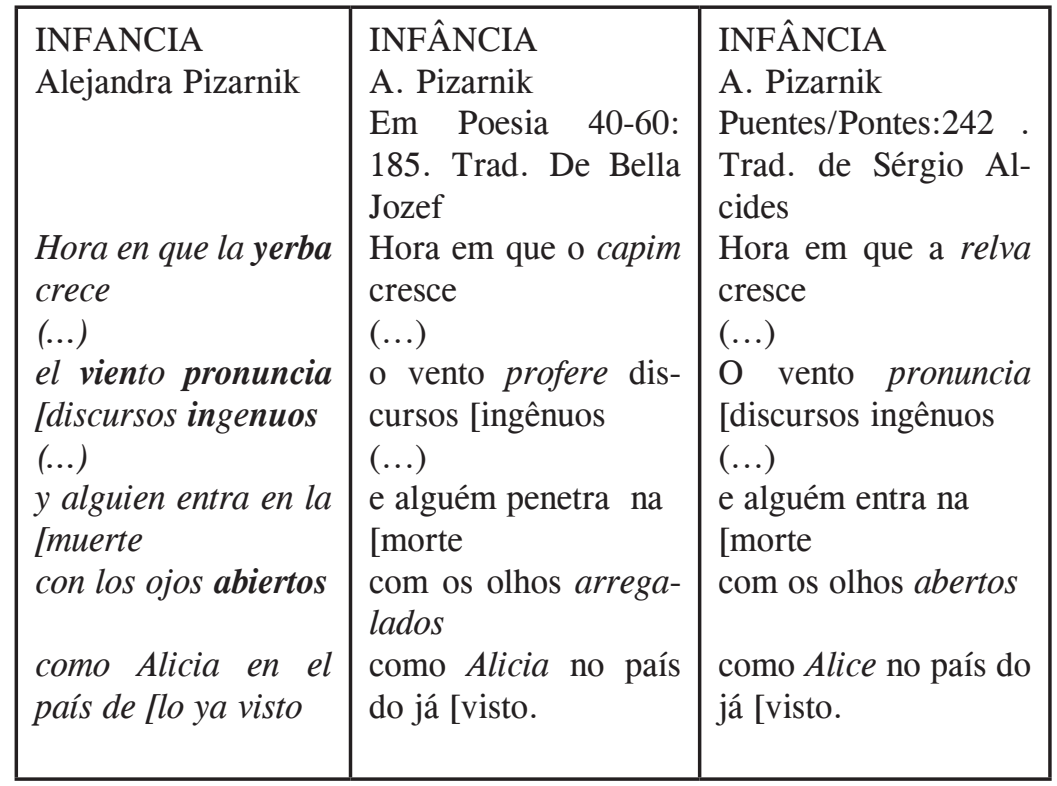

Em Poesia 40/60, paradoxalmente, a tradutora que explicita preocupação com a literalidade se distancia do original em opções como "olhos arregalados" ou "profere discursos". Nesse último caso, parece prevalecer a ressonância da expressão "proferir discursos", frequente no português brasileiro, mesmo que isso signifique afetar a aliteração de n no original de Pizarnik em: "viento pronuncia discursos ingenuos".

Finalizo estas observações sobre exemplos de tradução para refletir sobre questões de discursividade, fazendo referência aos versos finais do poema "el pájaro se desampara ..." de Gelman, incluído em Puentes/Pontes: 


\begin{tabular}{|c|c|}
\hline $\begin{array}{l}\text { O1el pájaro se desampara en su } \\
\text { o2vuelo /quiere olvidar las alas } \\
\text { (...) } \\
13 \text { con los ojos abiertos / canta } \\
\text { 14incompletamente } \\
\text { Juan Gelman }\end{array}$ & $\begin{array}{l}\text { 01o pássaro desampara-se em } \\
\text { 02seu voo / quer esquecer as asas / } \\
\text { (...) } \\
\text { 13de olhos abertos / canta } \\
\text { 14de incompletude } \\
\text { Juan Gelman } \\
\text { "Transcriações por Haroldo de } \\
\text { Campos" } \\
\text { (Puentes/Pontes:131.) }\end{array}$ \\
\hline
\end{tabular}

Na tradução do último verso, Haroldo de Campos opta, justamente, por não retomar a materialidade do advérbio com o sufixo -mente, por sua vez presente também no título do livro (Incompletamente $^{18}$ ) em que o poema foi originalmente publicado. Essa ressonância discursiva, que não deve ter passado inadvertida ao tradutor, não prevalece na opção do português "de incompletude". Ao pensarmos em tradução cultural, cabe considerar casos como o da materialidade desse advérbio, que ressoa em domínios de saber vinculados à poesia e à cultura rioplatense, como atesta o discurso de Monteleone na antologia, quando o ensaísta lembra:

\begin{abstract}
“(...) a poesia de Juan Gelman faz de sua pena um valor e de suas perdas um significado lírico. O vazio do perdido se assemelha na sua poesia ao vazio do nomeado, que precisamente ao calar nomeia o luto da perda. Desse paradoxo está feita a memória do poema de Gelman: canta no esquecimento; o poema nomeia 'o que cala' e assim repete a seu modo a dor, como o pássaro que a canta: incompletamente ${ }^{19}$. (Monteleone, Puentes/Pontes, 2003: 24.)
\end{abstract}

As observações que acabo de fazer estão longe de argumentar em favor da chamada literalidade em tradução. O propósito aqui é enfocar tópicos da materialidade verbal, trazidos à tona pelas traduções, para avançar na compreensão do funcionamento de línguas, discursividades e poéticas em antologias bilíngues. 


\section{Cartografia do traduzido e apresentação na antologia}

A construção composicional é, como se sabe, um dos elementos que definem um gênero discursivo (Bakhtin, 1984: 265). Assim, nas antologias, cabe perguntar-se sobre a relação entre a prática de crítica do paratexto e a apresentação efetiva do material compilado. Como observa Miguel Gomes (2006: 39-40) ${ }^{20}$, nas grandes antologias de poesia hispano-americana, os prólogos ou apresentam correspondências "quase perfeitas" entre autores e movimentos culturais, ou salientam a impossibilidade dessa correspondência (o que daria à obra seu caráter memorável). $\mathrm{O}$ autor lembra também da existência de "manifestações tendenciais", que parece ser o caso das antologias bilíngues aqui tratadas.

Em Puentes/Pontes, na seção dedicada à poesia argentina, Monteleone delineia seis territórios, que congregam poetas de diferentes épocas e contextos. Eles são: “A poesia de sujeito lírico, biografia e memória” (com poemas de César Fernández Moreno, Juan Gelman e Juana Bignozzi); "A voz do duplo" (que corresponde à obra de Alejandra Pizarnik e Susana Thénon); "Poema e Espaço Sagrado" (com seleções da poesia de Amelia Biagioni, Olga Orozco, Héctor Viel Témperley e Francisco Madariaga); "Fabulações da persona", (que inclui poemas de Leónidas Lamborghini, Néstor Perlongher, Aldo Oliva e María del Carmen Colombo); "Percepções do objeto" (correspondente a poemas de Edgar Bayley, Alberto Girri, Roberto Juarroz e Joaquín Gianuzzi) e "Contemplação e poema" (referido à obra de Hugo Padeletti; Arturo Carrera e Diana Bellessi) (cf. Monteleone, Puentes/Pontes, 2003: 22-34). Contudo, a apresentação efetiva dos poemas na antologia acontece em ordem alfabética, por sobrenome de autor. Essa opção não é sem consequências para as condições discursivas de produção de leitura, sobretudo do leitor brasileiro. Um "detalhe" relacionado é que, respeitando costumes de cada país, a sequência de poetas brasileiros aparece organizada, no índice e no corpo da antologia, pela ordem alfabética do primeiro nome, enquanto que os poetas 
argentinos estão relacionados pela ordem de seus sobrenomes. Essa opção é, evidentemente, adequada para os leitores à procura dos autores de seu próprio país, mas cabe perguntar-se sobre os efeitos em relação aos leitores de cada país na procura dos autores e poemas do outro. Voltarei a esta questão, após referir-me à construção composicional de Poesia 40/60.

$\mathrm{Na}$ antologia de Bella Jozef, o material é abordado criticamente no prefácio em torno da noção de gerações literárias: de 40, 50 e 60. Referindo sinteticamente, a geração de quarenta é representada no discurso como: "grupo, vasto e difuso, (...) [com] várias linhas expressivas. Uma delas é o neo-romanticismo (...). Mas houve outras tendências [como] (...) a poesia pura e a indagação sobre conflitos do ser e seu tempo, a exaltação da infância e da terra natal. (...). Com isto, integram-se poetas das províncias..." (Jozef, Poesia 40/60: 1990: 18). A geração de 50 é dividida em "dois movimentos: o Surrealismo, (...) a tentativa de uma total liberação dos elementos irracionais latentes no inconsciente e o Invencionismo, representado pela revista Poesía Buenos Aires (...), com uma poesia cerebral." (op. cit.: 20). A geração de 60 "receb[eu] influência da linguagem coloquial, enfatizando (...) a dessacralização da lírica e, (...) incorpor[ou] a circunstância política e continental com adoção de formas sintéticas derivadas da publicidade e da história em quadrinhos" (op.cit.: 23) ${ }^{21}$. A apresentação efetiva dos poemas em Poesia 40/60 acontece por ordem de ano de nascimento dos poetas. Eles são (na ordem de apresentação na antologia): Aldo Pellegrini, Juan José Ceselli, Enrique Molina, Carlos Latorre, Manuel J. Castilla, Carlos Alberto Débole, Atilio Jorge Castelpoggi, Edgar Bayley, Alberto Girri, Olga Orozco, Roberto Juarroz, Francisco Madariaga, Raúl Gustavo Aguirre, Rubén Vela, Alfredo Veiravé, Leónidas Lamborghini, María Helena Walsh, Juan Gelman, Federico Gorbea, Juan José Hernández e Alejandra Pizarnik.

$\mathrm{O}$ critério de data de nascimento se apresenta mais vinculado à contextualização histórica do que o critério de compilação por ordem alfabética, mas pode também criar a questionável ilusão de 
correspondência entre o histórico e o cronológico. A representação discursiva da linearidade temporal pode obliterar, por exemplo, que poetas mais novos influenciam outros nascidos anteriormente ou que um poeta, como por exemplo Gelman, nascido em 1930, que continua produzindo e é muito lido na atualidade, seja "menos contemporâneo" que outro nascido recentemente ${ }^{22}$.

A discrepância ou não entre a crítica do estudo preliminar e a estrutura composicional de uma antologia decorre sempre de opções atreladas a motivos de ordens diversas ${ }^{23}$. O que interessa ao analista de discurso e estudioso do gênero antologia é interrogar-se sobre consequências dessas opções, em função dos efeitos de memória e das condições de produção de leitura, visando à compreensão do funcionamento e aprimoramento do gênero na atualidade. Há antologias organizadas em total consonância entre a crítica do estudo preliminar e sua construção composicional. Esse é o caso, por exemplo, da antologia monolíngue de Perednik, Nueva poesia argentina durante la dictadura (1976 - 1983). Nessa antologia, a apresentação dos poemas segue diretamente o critério escolhido de incluir autores e poemas publicados nas revistas de poesia dessa época, a saber: 1) Poddema e Signo Ascendente (poética surrealista); 2) La Danza del Ratón, o folhetim Oliverio, El Ladrillo (poesia marcada, segundo Perednik, pelo tratamento de temas imediatos e pela linguagem coloquial); 3) Último Reino (poética neo-romântica); 4) XUL, Signo viejo y nuevo: poesia caracterizada por esse antologista como de "transformação (...) das líricas dominantes (...) e preocupação (...) com a linguagem e a forma" (op. cit.: 18) - espaço do neobarroco (ou neobarroso) -; 5) Sátura: "poética de voz pessoal - e não vozes subsumidas à moda, imitação ou escola" (Ibidem); 6) Edições Mano de Obra: poética próxima do aforismo (Idem: 19) ${ }^{24}$.

Obviamente, a função do antologista não é facilitar, didaticamente, o caminho do leitor. Pode esperar-se que este circule pela apresentação de autores e poemas, dialogando criticamente com eles e com o organizador da antologia. De qualquer forma, o ponto 
que gostaria de salientar é que, no caso específico das antologias bilíngues, nas quais o leitor nem sempre está familiarizado com a cultura, os autores ou as obras compiladas, é preciso tratar especificamente a questão da estrutura composicional, a fim de prever consequências para as condições discursivas de produção de leitura, evitando obstáculos eventuais na circulação das antologias e na difusão da poesia compilada.

\section{Considerações Finais}

Como foi mostrado, o espaço do projeto tradutório no paratexto destas antologias não difere muito do que é mais usual em compilações bilíngues de poesia ibero-americana, isto é, o tratamento explícito e detalhado da questão é relativamente reduzido ${ }^{25}$. Essa tendência à "invisibilidade" da tradução, em alguns casos, extendese até o registro de créditos aos tradutores ${ }^{26}$. Isto não acontece em Poesia 40/60, nem em Puentes/Pontes, cujos créditos de tradução estão registrados cuidadosamente.

Em relação à comparação de traduções - em especial de mais de uma tradução do mesmo original, a meu ver, análises discursivas como as apresentadas permitem refletir sobre questões da materialidade poética nas diferentes traduções, bem como no original, à luz das opções tradutórias. No caso específico das compilações bilíngues português/espanhol, os exemplos discutidos confirmam que, precisamente pela proximidade sistêmica das línguas, o componente discursivo talvez requeira uma atenção especial. Isso inclui interrogar-se sobre novos projetos de antologias anotadas, com maior discussão sobre opções tradutórias e sobre ressonâncias discursivas nas culturas de partida e de chegada.

Finalmente, sobre a relação: cartografia crítica no paratexto e apresentação do material compilado, um dos desafios nas antologias bilíngues parece ser uma maior consideração das especificidades do público leitor, sobretudo no caso de culturas "tão semelhante[s] 
(...) quanto radicalmente diferenciada[s]" (Buarque de Hollanda, Puentes/Pontes, 2003: 279). Isso poderá contribuir para ampliar a circulação efetiva do gênero na América Latina, onde um outro desafio concomitante continua sendo a ampliação do público leitor. Assim, questões que também se impõem hoje em dia são as articulações entre diferentes suportes e mídias ${ }^{27}$ e novos tratamentos do intercultural nos projetos antológicos. A meu ver, aprofundar as propostas conjuntas de antologias bi ou plurinacionais é um caminho promissor, no contexto atual de integrações regionais, visando a incrementar a participação do âmbito literário-cultural na consolidação dessas integrações.

\section{Notas}

1. Ver, por exemplo, B. Benedict, 1996 e B. Mujica, 1997.

2. Ver Delabastita, 2008. Agradeço a Walter C. Costa o envio da versão ainda inédita desse texto.

3. Trata-se do Projeto Antologias, Discurso e Práticas Letradas (www.antologiasediscurso.iel.unicamp.br), que coordeno no IEL-UNICAMP e é desenvolvido com apoio do CNPq e da FAPESP. Fica aqui registrado meu reconhecimento a essas instituições de apoio à pesquisa. Esse projeto está vinculado também ao Centro de Pesquisa em Estudos Hispano-americanos (CEHISP) do IEL.

4. Publicada em São Paulo pela editora Iluminuras, em 1990.

5. Publicada em Buenos Aires pela editora Fondo de Cultura Económica, em 2003.

6. Deve ficar registrado que essas antologias foram concretizadas, em grande 
parte, graças ao estímulo de May Lorenzo Alcalá e de Teresa Arijón, respectivamente, e ao apoio de fundações de incentivo à cultura, como costuma acontecer em projetos deste tipo.

7. Publicada em Genebra pela editora Patiño, em 1996.

8. Comunicação pessoal de J.-J. Courtine, após sua palestra no IEL-UNICAMP em novembro de 2003, quando o pesquisador apresentou resultados de suas análises do discurso político, no quadro de sua proposta de antropologia histórica (Courtine, 1989).

9. A ressonância discursiva é uma categoria de análise desenvolvida para o estudo de funcionamentos discursivos da paráfrase (Serrani, 2005: 90). A noção permite analisar a recorrência de palavras (sejam ou não da mesma família semântica), de construções (sejam ou não paráfrases do ponto de vista sintático) e de modos de dizer, que funcionam em um dado discurso construindo efeitos de sentido predominantes. Exemplos da implementação dessa noção na análise do discurso de antologias em Serrani (2008a e 2008b).

10. Os destaques em itálico são meus. Será assim sempre no caso de indicar ressonâncias discursivas em excertos. Haverá indicação específica quando o destaque for do original.

11. Especificamente, Josely Vianna Baptista traduziu Aldo Oliva e Néstor Perlongher. Renato Rezende fez a tradução dos poemas de Amelia Biagioni, Edgar Bayley, Francisco Madariaga, Joaquín O Gianuzzi, Juana Bignozzi, Leónidas Lamborghini e Roberto Juarroz. Sérgio Alcides traduziu Alberto Girri, Alejandra Pizarnik, Arturo Carrera, César Fernández Moreno, Diana Bellessi, Héctor Viel Témperley, Hugo Padeletti, Juan Gelman, María del Carmen Colombo, Olga Orozco e Susana Thénon.

12. A tradução é minha. Sempre será assim nos casos em que o título da obra constar em outra língua nas Referências Bibliográficas.

13. Particularmente, em relação ao discurso poético, ver Krieger e Clark in Preminger and Brogan (1993: 739). 
14. Os caracteres em itálicos e os números que anteceden os versos foram acrescentados por mim para facilitar a localização de trechos do poema durante a discussão.

15. Em um trabalho recente discuto em detalhe os funcionamentos discursivos de ressonâncias de indeterminação de agente, em diversos gêneros de discurso (Serrani, 2009).

16. De fato, essa questão foi levantada nesses termos por membros do público na ocasião de evento na PGET-UFSC (Pós-Graduação em Estudos de Tradução da Universidade Federal de Santa Catarina), quando apresentei uma versão preliminar desta discussão.

17. Agradeço a Mauri Furlan por suas considerações sobre esta possibilidade de tradução durante o referido evento.

18. Publicado pela editora Seix Barral, Buenos Aires, 1997.

19. Esse itálico não é do original.

20. Agradeço a Walter C. Costa, que me ofereceu a antologia de poesia mexicana com esse texto crítico de Gomes.

21. Ocupei-me especialmente da representação da poesia argentina dos anos 60 no trabalho da revista Aletria 18 (ver Referências Bibliográficas).

22. Ver Croce, M. 1998.

23. Como, entre outras, as exigências do âmbito editorial.

24. O objetivo aqui é ilustrar a relação direta entre os critérios de crítica e a apresentação dos poemas na antologia. Para uma discussão das pautas de crítica, ver, entre outros, Fondebrider (2006).

25. Essa afirmação está baseada no estudo sobre antologias bilíngües de poesia brasileira e hispano-americana realizado, com apoio da Fapesp, na Universida- 
de de Columbia, EUA (resultados em Serrani, 2006). Dentre as exceções, cabe mencionar, por exemplo, a antologia bilíngüe (português/inglês) de Elizabeth Bishop e Emanuel Brasil, An Anthology of Twentieth Century Brazilian Poetry. No paratexto, além da discussão detalhada do projeto tradutório na introdução, após a apresentação dos poemas, há uma seção de notas sobre a trajetória e obras publicadas de editores e tradutores. O relevo dado à tradução nessa antologia fica atestado também na diagramação da capa, na qual constam relacionados autores e tradutores.

26. Em se tratando de tradução do/a(s) organizador/a(s) de uma antologia, há casos em que não fica claro para o leitor o tradutor responsável pela versão de cada poema na antologia. A valiosa antologia de mulheres poetas negras brasileiras Enfim... Nós!Finally Us!, de Alves/Richardson-Durham parece ilustrar um desses casos.

27. Dentre os exemplos, pode lembrar-se o caso da compilação monolíngüe Monstruos - Antología de la joven poesia argentina, de Arturo Carrera, que se concretizou primeiro em suporte eletrônico e, posteriormente, na forma de livro em papel.

\section{Bibliografia}

BAKHTIN, M. (1984): Esthétique de la création verbale. Trad: Alfreda Aucouturier. Paris. Gallimard. (Ed. Bras.: (2003) Estética da Criação Verbal. Trad: Paulo Bezerra. São Paulo: Martins Fontes.)

BENEDICT, B. (1996): Making the Modern Reader: Cultural Mediation in Early Modern Literary Anthologies. Princeton N. J.: Princeton University Press.

CASANOVA, P. (2002): A República Mundial das Letras. São Paulo: Estação Liberdade. 
CLARK, M. e KRIEGER, M. (1993): "Poetic Meaning" in PREMINGER, A. e T. V. F. BROGAN: The New Princeton Encyclopedia of Poetry and Poetics. Princeton, NJ. Princeton University Press, pp. 739-743.

COURTINE, J.-J. (1989): “Corps et discours: éléments d'histoire des pratiques langagières et expressives”. Dossier de Thèse d'Etat. Université de Paris X Nanterre.

CROCE, M. (1998): "Poesia argentina año 2000". Cuadernos de "El Matadero", 1. Serie Revistas Especializadas. Buenos Aires: Universidad de Buenos Aires.

DELABASTITA, D. (2008): “Anthologies, Translations and European Identities”. DELABASTITA, D.; P. Franssen e De Vos, J.. Shakespeare and European Politics. Newark: University of Delaware Press.

EAGLETON, T. (2007): How to Read a Poem. Oxford: Blackwell Publishing.

FONDEBRIDER, J. (2006): Tres décadas de poesía argentina 1976 -2006. Buenos Aires: Libros del Rojas.

FOUCAULT, M. (1985): La arqueología del saber. Tradução: Aurelio G. del Camino. México: Siglo XXI Editores, $1985\left(11^{\mathrm{a}}\right.$. edição - $1^{\mathrm{a}}$. edição francesa: 1969).

. (1987): As Palavras e as Coisas. Tradução Salma Muchail. São Paulo:

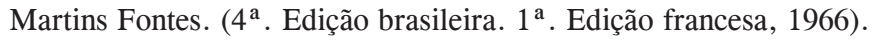

GENETTE, G. (2002): Seuils. Paris: Éditions du Seuil (1 ${ }^{\text {a }}$ Ed. 1987).

GOMES, M. (2006): "Después de los ismos: La voluntad de historia em la poesía mexicana reciente". Mendiola, V; M. Zapata e M. Gomes: Tigre de la sed - antología de poesía mexicana contemporánea 1950-2005. Madrid: Hiperión.

MUJICA, B. (1997): “Teaching Literature: Canon, Controversy and the Literary Anthology" Hispania, vol 80, nº. 2. 
NORA, P. (1996): "Entre mémoire et histoire - La problématique des lieux", in NORA P. (Ed.) Les Lieux de mémoire 3. v. Paris: Gallimard, pp.,23-43.

PÊCHEUX, M. (1988): Semântica e Discurso. Uma Crítica à Afirmação do Óbvio. Tradução: E. Orlandi, S. Serrani, L. Chacon e M. Côrrea. Campinas: Editora da UNICAMP (1a. edição em francês: 1975.)

. (1990a): L'Inquiétude du discours. Textos de M. Pêcheux escolhidos e apresentados por M. Maldidier. Paris, Éditions des Cendres.

. (1990 b): O Discurso. Estrutura ou Acontecimento. Tradução: E. Orlandi. Campinas: Pontes. Serrani, S. (2005): Discurso e Cultura na Aula de Língua. Campinas: Pontes.

. (2006): "Identidade e Representação do Brasil em Antologias Poéticas Bilíngues", in Magalhães, I., M. Grigoletto e M. J. Coracini (Orgs.). Práticas Identitárias - Língua e Discurso. São Carlos: Editora Claraluz.

. (2008a): "Antologia: escrita compilada, discurso e capital simbólico". Alea. Estudos Neolatinos, v. 10 n. 2, p. 270-287, Rio de Janeiro, 2008. Também, em:

http://www.scielo.br/scielo.php/script sci_serial/pid_1517-106X/lng_en/nrm iso

. (2008b): “Antologias, Discurso e Memória Cultural - O Dialogismo em Compilações Bilíngues de Poesia Argentina”. Revista Aletria 18. Belo Horizonte: UFMG, no prelo.

. (2009): "Lengua española y estudios del discurso". Revista Signo y Seña, Buenos Aires: UBA, no prelo. 


\section{Bibliografia Fuente - Antologias Referidas}

ALVES, M. e C. RICHARDSON DURHAM (1995): Enfim...nós! Finally...us!, Colorado Springs, CO: Three Continents Press.

BISHOP, E. e E. BRASIL (1997): An Anthology of Twentieth-Century Brazilian Poetry; Middletown, CN: Wesleyan University Press (1a. edição: 1972).

BUARQUE DE HOLLANDA, H. e MONTELEONE, J. (2003): Puentes/Pontes - Antologia de Poesia Argentina e Brasileira Contemporânea. Buenos Aires/ México: Fondo de Cultura Económica, 2003.

CARRERA, A. (2001): Monstruos - Antología de la joven poesia argentina. Buenos Aires: Fondo de Cultura Económica/ICI.

JOZEF, B. (1990): Poesia Argentina 1940-1960 de Bella Jozef. São Paulo: Iluminuras.

PEREDNIK, J. (1992): Nueva poesía argentina durante la dictadura (19761983). Buenos Aires: Calle Abajo (1 ${ }^{\text {a }}$. edição 1989).

SALAS, H. (1996): Poésie argentine du XXe siècle. Tradução de Nicole Priollaud. Genève : Les Éditions Patiño. 